\title{
Shear Strength of Thin-Webbed Post-Tensioned Beams
}

\author{
by Miguel Fernández Ruiz and Aurelio Muttoni
}

\begin{abstract}
This paper investigates the load-carrying mechanisms and the strength of thin-webbed, post-tensioned beams failing by crushing of the web. The shear strength in these members is significantly reduced because of the state of cracking in the web and because of the disturbance in the flow of stresses introduced by the prestressing tendons. The interaction between both effects is investigated. To that end, the results of six full-scale tests performed on actual prestressed beams extracted from a girder bridge are presented. The results are analyzed and various approaches for the modeling of such members are investigated and compared.
\end{abstract}

Keywords: bridge girder; concrete crushing; post-tensioning; shear strength; stress field; tendons; testing; web.

\section{INTRODUCTION}

Since the inception of reinforced concrete, and especially since the development of prestressed concrete, girder bridges have always been simple, economic, and suitable choices for small- to medium-span bridges. The erection of thin-webbed girders with precast elements and significant post-tensioning tendons has been common practice since the 1950s and 1960s. ${ }^{1}$ Many existing bridges of this type present a ratio between the tendon diameter and the width of the web close to one-half. In the past decades, there has been a tendency to increase the width of the webs with respect to the tendon diameters. Thus, usual, current values of the tendon-to-width ratio have decreased to one-third. This is explained by the increase in the concrete cover requirements as well as by the consideration of the strength reduction due to the presence of tendons ${ }^{2}$ (which was not included in most codes of practice until the end of the 1980s). Recent increases in strength requirements and traffic loads have raised the question of the suitability of some existing bridges of this type.

The strength reduction due to the tendon presence is taken into account in most current design codes by means of a strength reduction factor $\eta_{D}$. The value of $\eta_{D}$ depends on the duct diameter, on the duct material (steel or plastic), and on the injection (or not) of the tendon. ${ }^{2}$ This factor can be introduced in the analysis performed using two different, but equivalent, approaches:

1. Defining an effective width of the web $b_{\text {eff }}$ obtained by reducing the actual width of the web by $\eta_{D}\left(b_{e f f}=b_{w} \eta_{D}\right)$. The overall strength of the member is thus affected because the shear carried by a web requires the development of an inclined compression field whose strength depends on the effective width of the web; and

2. Alternatively, this reduction can be introduced by reducing the compressive strength of the concrete of the web by the same factor $\left(f_{c e, w}=f_{c, w} \eta_{D}\right)$ and considering the actual width of the web $b_{w}$.

The strength of the inclined compression field is also affected by the state of cracking in the web. It is thus necessary to consider another strength reduction factor $\eta_{\varepsilon}$ to account for this effect in the compression field. Usually, a multiplicative formulation is adopted for the interaction between these two factors $\left(\eta_{D}\right.$ and $\left.\eta_{\varepsilon}\right)$.

Using this approach, the strength and the angle of the compression struts of the web can be determined (Fig. 1). The angle is usually limited to a given value (21.8 degrees in Eurocode $2^{3}$ and AASHTO LRFD ${ }^{4}$ ), although values significantly smaller than the usual limits are sometimes adopted in the checking of actual bridges. ${ }^{5}$

This paper presents the results of an experimental investigation performed on five beams extracted from a thinwebbed bridge replaced after 36 years of service. The web of the bridge $(125 \mathrm{~mm}$ [5 in.] thick) contained two $60 \mathrm{~mm}$ (2.4 in.) tendons, with a tendon to web width ratio of 0.48 . The aim of the tests was to study the actual strength of thin post-tensioned webs and the interaction between the state of cracking in the web and the disturbance induced by the tendon. The experimental results are also used to investigate the suitability of several analytical approaches (stress fieldbased approaches and various design codes) for the modeling of such members.

\section{RESEARCH SIGNIFICANCE}

Some existing girder bridges with thin post-tensioned webs do not satisfy current shear strength requirements. This paper details the experimental results obtained from six tests performed on beams of this type failing by web crushing. The experimental results are used to explain the behavior of these members and to investigate the interaction between the



Fig. 1-Post-tensioned girder with thin web: inner forces in cross section, web thickness $\mathrm{b}_{\mathrm{w}}$, tendon diameter $\mathrm{d}_{\mathrm{D}}$, and compression field angle $\theta$.

ACI Structural Journal, V. 105, No. 3, May-June 2008.

MS No. S-2006-451.R1 received December 5, 2006, and reviewed under Institute publication policies. Copyright (C) 2008, American Concrete Institute. All rights reserved, including the making of copies unless permission is obtained from the copyright proprietors. Pertinent discussion including author's closure, if any, will be published in the MarchApril 2009 ACI Structural Journal if the discussion is received by November 1, 2008. 
Miguel Fernández Ruiz is a Lecturer at the Ecole Polytechnique Fédérale de Lausanne, Lausanne, Switzerland. He received his diploma and $P h D$ in civil engineering from the Polytechnical University of Madrid, Madrid, Spain, in 2001 and 2004, respectively. His research interests include the serviceability behavior of structures, bond, shear and punching shear, and the modeling of structural concrete using stress fields.

ACI member Aurelio Muttoni is a Professor and Head of the Structural Concrete Laboratory at the Ecole Polytechnique Fédérale de Lausanne. He received his diploma and PhD in civil engineering from the Swiss Federal Institute of Technology, Zurich, Switzerland, in 1982 and 1989, respectively. His research interests include the theoretical basis of the design of reinforced concrete structures, shear and punching shear, fiber-reinforced high-strength concrete, soil-structure interaction, and the conceptual design of bridges.

state of cracking in web and the presence of tendons. Also, the experimental results are used to investigate the suitability of several analytical approaches to estimate the shear strength of such members.

\section{EXPERIMENTAL CAMPAIGN}

Six tests were performed using beams extracted from the viaduct Viadotto Sopra le Cantine in Switzerland. The bridge was erected in 1967 (Fig. 2) using limited construction equipment due to the location of the bridge. The weight of the beams was consequently reduced to a minimum. The webs were $125 \mathrm{~mm}$ ( 5 in.) thick, with two post-tensioning tendons placed in $60 \mathrm{~mm}$ (2.4 in.) diameter corrugated steel ducts.

Also, due to weight reasons, each beam of the bridge was assembled from two $10 \mathrm{~m}(32.8 \mathrm{ft})$ long half-span precast elements. These elements were prestressed in the precasting yard by means of 12 straight wires of $7 \mathrm{~mm}(0.27$ in.) diameter in the lower flange. Once the precast elements were placed, the deck slab of the bridge and the diaphragms over piles and at midspans were cast in place. Two post-tensioning tendons each consisting of 27 wires of $7 \mathrm{~mm}(0.27 \mathrm{in}$.) in diameter were post-tensioned at a later stage to create a continuous five-span bridge. The post-tensioning tendons were thus the only reinforcement present at midspan. The peculiar layout


Fig. 2-Cantine viaduct beams (Switzerland): (a) construction, 1967; and (b) testing at Ecole Polytechnique Fédérale de Lausanne (EPFL), 2004. of the tendons, with a larger curvature at midspan than over the support, as shown in Fig. 3(c), was aimed at reducing the post-tensioning secondary (redundant) moments.

The bridge was replaced in 2003 because of the deterioration of the deck slab and bearings of the bridge. Five of its beams without signs of deterioration were tested to failure at the Structural Concrete Laboratory of EPFL (Ecole Polytechnique Fédérale de Lausanne, Switzerland [Fig. 2(b) and 3(a)]). The tests aimed at investigating the actual behavior of these members under various loading conditions (Fig. 3(a) and 4)). Detailed information on the testing and main results of this campaign can be found in Reference 6 .

\section{Materials}

The concrete properties for the precast elements and the deck slab were tested for all specimens by extracting a series of cylinders and prisms from each specimen. A summary of the results obtained is presented in Table 1.

Also, the main properties of the various types of steel used in the precast elements- the deck slab, the tendons, and the prestressing wires-were measured. A summary is presented in Table 2.

\section{Prestressing force}

Measurements were taken $^{7}$ to determine the actual remaining amount of prestressing before testing the specimens. It was found that for the various specimens, a mean value of $\sigma_{p, \infty} \approx 530 \mathrm{MPa}(77 \mathrm{ksi})$ remained. Taking into account that the initial prestress was $\sigma_{p, 0} \approx 1190 \mathrm{MPa}(172 \mathrm{ksi})$, this means that only $45 \%$ of the initial prestress remained. Such significant losses can be explained by the strong prestressing of the beams, both in the precasting yard and after placement of the beams.

\section{Table 1-Measured properties of concrete for tested specimens}

\begin{tabular}{|c|c|c|c|c|c|c|}
\hline Test & SH1 & SH2 & SH3 & SH4a & SH4b & SH5 \\
\hline \multicolumn{7}{|c|}{ Precast element: prisms $h / b_{w} / d, \mathrm{~mm}$ (in.) $=240 / 125 / 120(9.44 / 4.92 / 4.72)$} \\
\hline $\begin{array}{l}f_{c m}, \mathrm{MPa} \\
(\mathrm{ksi}), \mathrm{No} .\end{array}$ & $\begin{array}{c}53.4 \\
(7.74), 4 \\
\end{array}$ & $\begin{array}{c}52.3 \\
(7.58), 4 \\
\end{array}$ & $\begin{array}{c}55.8 \\
(8.08), 2 \\
\end{array}$ & $\begin{array}{c}49.5 \\
(7.17), 3 \\
\end{array}$ & $\begin{array}{c}60.0 \\
(8.69), 2 \\
\end{array}$ & $\begin{array}{c}47.2 \\
(6.84), 4 \\
\end{array}$ \\
\hline \multicolumn{7}{|c|}{ Deck slab: cylinders height/diameter, mm (in.) $=200 / 100(7.87 / 3.93)$} \\
\hline $\begin{array}{l}f_{c m}, \mathrm{M} \\
(\mathrm{ksi}),\end{array}$ & $\begin{array}{r}48.2 \\
(6.98), \\
\end{array}$ & \begin{tabular}{|c|}
44.9 \\
$(6.50), 3$ \\
\end{tabular} & $\begin{array}{r}53 . \\
(7.78 \\
\end{array}$ & $\begin{array}{r}59 . \\
(8.58 \\
\end{array}$ & $\begin{array}{c}59.2 \\
(8.58), 2 \\
\end{array}$ & $\begin{array}{c}46.2 \\
(6.69), 3 \\
\end{array}$ \\
\hline $\begin{array}{l}E_{c m}, \mathrm{MPa} \\
(\mathrm{ksi}), \mathrm{No} .\end{array}$ & $\begin{array}{c}33,500 \\
(4850), 1 \\
\end{array}$ & $\begin{array}{c}36,000 \\
(5220), 1 \\
\end{array}$ & $\begin{array}{r}35,5 \\
(5140 \\
\end{array}$ & $\begin{array}{c}37,000 \\
(5360), 1\end{array}$ & $\begin{array}{c}37,000 \\
(5360), 1 \\
\end{array}$ & $\begin{array}{r}36,2 \\
(525 \\
\end{array}$ \\
\hline
\end{tabular}

Table 2-Measured reinforcing and prestressing steel properties

\begin{tabular}{c|c|c|c|c|c}
\hline Type & $d_{b}, d_{w}, \mathrm{~mm}(\mathrm{in})$. & $f_{y m, 0.2 \%}, \mathrm{MPa}(\mathrm{ksi})$ & $f_{t m}, \mathrm{MPa}(\mathrm{ksi})$ & $\varepsilon_{u}, \%$ & No. \\
\hline \multicolumn{6}{c}{ Web and lower flange } \\
\hline $\begin{array}{c}\text { Cold } \\
\text { worked }\end{array}$ & $8(0.315)$ & $624(90.4)$ & $747(108)$ & 5.7 & 5 \\
\hline $\begin{array}{c}\text { Cold } \\
\text { worked }\end{array}$ & $10(0.394)$ & $582(84.3)$ & $730(106)$ & 4.9 & 5 \\
\hline \multicolumn{6}{c}{ Deck slab } \\
\hline Hot rolled & $12(0.472)$ & $392(56.8)$ & $544(78.8)$ & 15.2 & 3 \\
\hline Hot rolled & $20(0.787)$ & $374(54.2)$ & $521(75.5)$ & 11.5 & 1 \\
\hline Hot rolled & $26(1.02)$ & $371(53.7)$ & $560(81.1)$ & 15.5 & 1 \\
\hline \multicolumn{6}{c}{ Prestressing wires of post-tensioning tendons } \\
\hline Wires & $7(0.275)$ & $1457(211)$ & $1738(251)$ & 4.5 & 3 \\
\hline \multicolumn{6}{c}{ Prestressing wires of precast elements } \\
\hline Wires & $7(0.275)$ & $1340(194)$ & $1707(247)$ & 4.6 & 5 \\
\hline
\end{tabular}




\section{Testing}

The test setup is shown in Fig. 3(a) and 4. It can be noted that an eccentric external axial force $N$ was applied during the test, providing enough flexural strength. This force was necessary to avoid flexural failure because the tested girders were single-span beams, whereas the original bridge girders were continuous beams. It can be noted that Specimen SH4 was tested twice, changing the loading and support conditions and, thus, the location of the shear failure. The loads applied at failure for each test are given in Table 3.

The strains in the web and in the upper flange of the girder were measured by following the in-plane deformation of a mesh of $270 \mathrm{~mm}$ (10.6 in.) equilateral triangles. Based on these results, the principal strains and their directions could be determined. In the lower flange, because of its limited height, only measurements of the longitudinal strain along a

\section{Table 3-Applied loads at failure}

\begin{tabular}{c|c|c}
\hline Test & $V_{\text {test }}, \mathrm{MN}(\mathrm{kips})$ & $N_{\text {test }}, \mathrm{MN}(\mathrm{kips})$ \\
\hline $\mathrm{SH} 1$ & $1.49(333)$ & $3.58(801)$ \\
\hline $\mathrm{SH} 2$ & $1.26(281)$ & $2.02(452)$ \\
\hline $\mathrm{SH} 3$ & $1.53(343)$ & $3.76(840)$ \\
\hline SH4a & $1.12(250)$ & $0.693(155)$ \\
\hline SH4b & $1.67(338)$ & $2.45(549)$ \\
\hline SH5 & $1.66(371)$ & $2.98(667)$ \\
\hline
\end{tabular}

line at the centroid of the flange were performed. Other measurements, including forces, displacements (linearly variable displacement transducer [LVDT]), and rotations, were also taken. ${ }^{6}$

\section{Failure mode}

All specimens failed by web crushing along the prestressing tendons with spalling of the concrete cover in the failure zone. Figure 5 shows the cracking pattern for Specimens SH1 and SH3 after failure.

\section{MAIN RESULTS OF REPRESENTATIVE BEAM: TEST SH3}

In this section, the results of Specimen $\mathrm{SH} 3$ are presented in detail as a representative beam of the test series. The results of the other specimens are detailed in Reference 6 and summarized in Table 3.

The loading pattern and the load-midspan deflection curves are plotted in Fig. 6. Initially, the beam was only loaded with a shear force $V$ up to $0.81 \mathrm{MN}$ (181 kips), after which the external axial force $N$ was also gradually applied.

At failure, significant strains were measured in both flanges and in the web. Compressive longitudinal strains larger than $2 \%$ were measured in the upper flange (refer to Fig. 7(a)). In the lower flange (Fig. 7(b)), a crack width of $11 \mathrm{~mm}$ (0.43 in.) was measured at the joint between the two

(a)

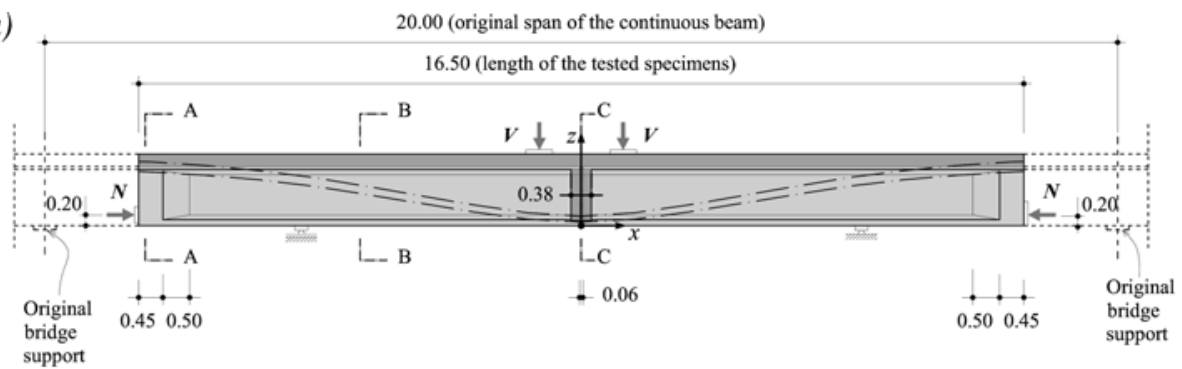

(b)

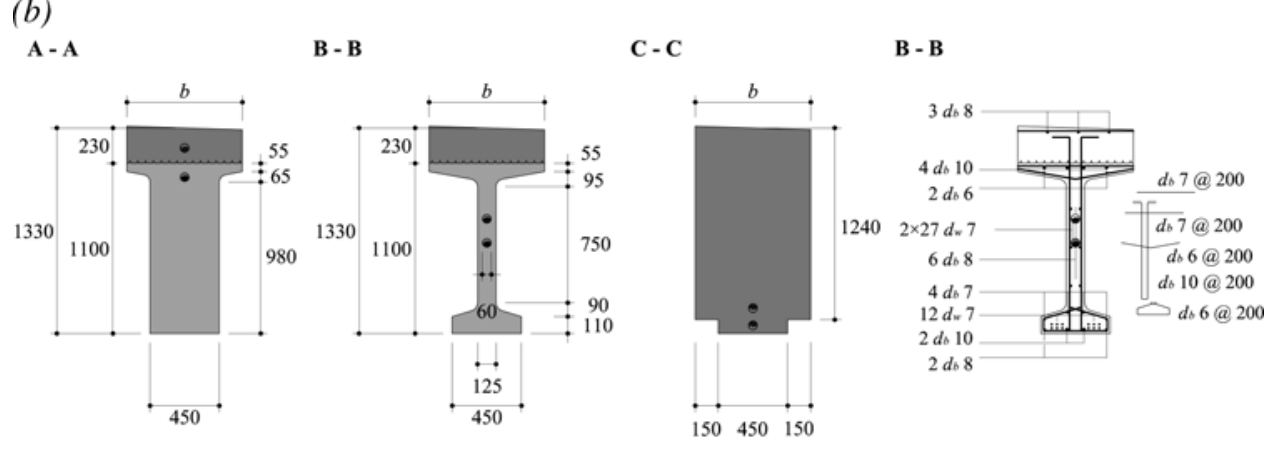

(c)

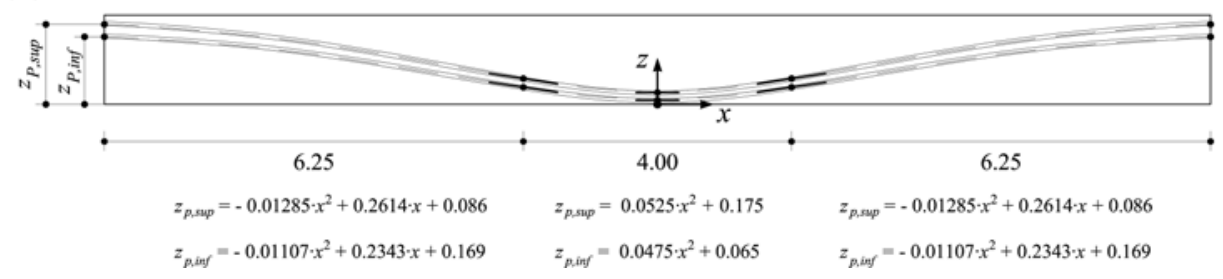

Fig. 3-Geometry, reinforcement, and prestress layout of beams: (a) longitudinal view (dimensions in meters); (b) cross sections of beams and reinforcement detail in Section B-B (dimensions in $\mathrm{mm}$ ) (upper flange width $\mathrm{b}=745 \mathrm{~mm}$ (29.3 in.) for all specimens except Specimen SH4 where $\mathrm{b}=705 \mathrm{~mm}$ (27.7 in.) (dimensions in $\mathrm{mm}$ ); and (c) prestress layout (axis in meters). (Note: $1 \mathrm{~m}=39.37 \mathrm{in}$.; $1 \mathrm{~mm}=0.03937 \mathrm{in}$.) 
precast elements. The longitudinal tensile strain in the precast elements was larger than $2 \%$. In the web, vertical strains larger than 5\%o were measured, indicating extensive stirrup yielding (refer to Fig. 7(c)). It should be noted that the strains were measured from the beginning of the test. Thus, the strains corresponding to the initial prestressing and its losses are not included.

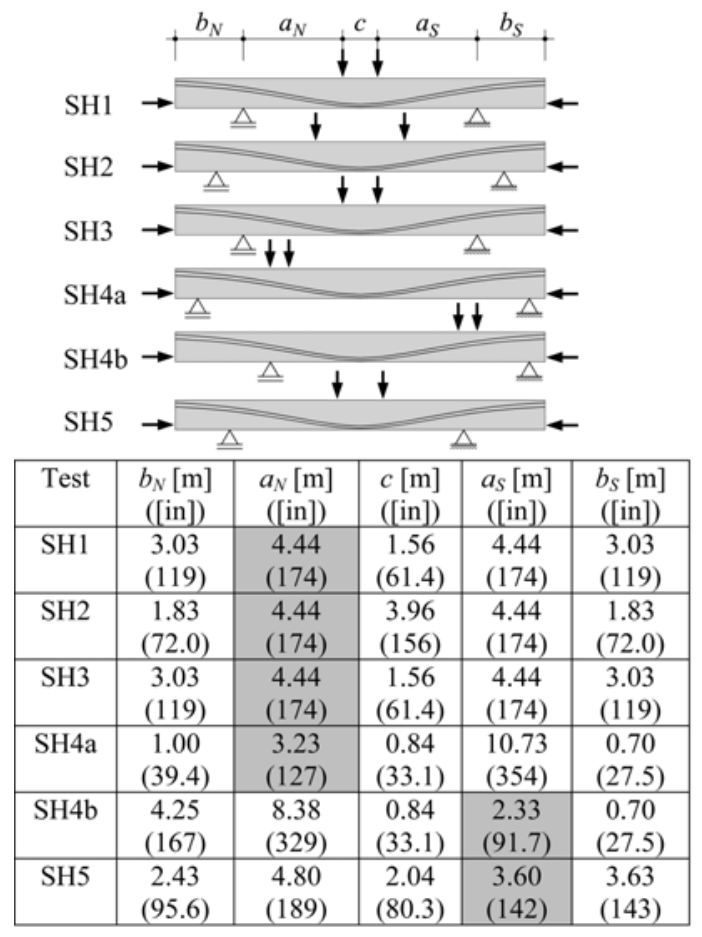

Fig. 4-Loading patterns for test performed and failure zone (shaded cells in table).
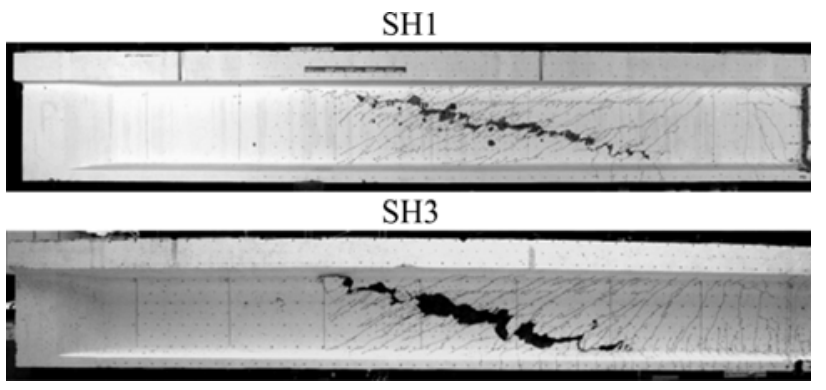

Fig. 5-Cracking pattern and concrete spalling after failure for Specimens SH1 and SH3.



(a)



(b)
Fig. 6-Beam SH3: (a) V-N loading pattern (with unloadingreloading cycle); and (b) plot of midspan deflection versus applied load.
Figure 8 shows the longitudinal and vertical strain profiles of Beam SH3 at various load levels. It can be noted (Fig. 8(a)) that plane sections remain approximately plane except in the vicinity of the tendons where a significant increase in the longitudinal strains is observed. Also, vertical strains (Fig. 8(b)) are not uniform in a given section, with larger strains above the tendon than below. These results (confirmed by the other specimens tested) indicate that a strain localization developed at the level of the tendons and that the tendons were actively interacting in the structural response of the member.

This interaction is further investigated in Fig. 9, where the principal compressive strain directions are shown for two load steps. Figure 9(a) plots the strain state for a small value of the


(c)

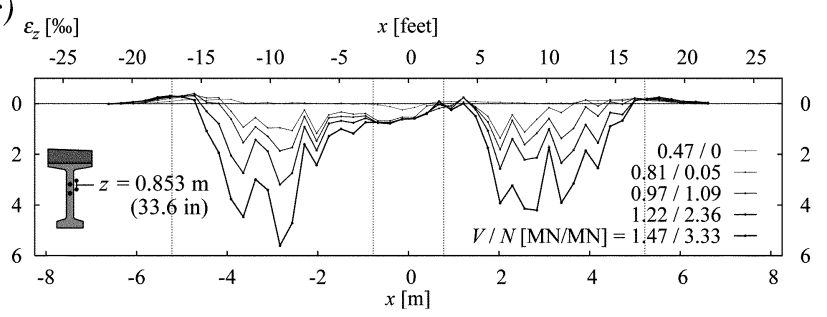

Fig. 7-Plots of strains in Beam SH3 at various load levels: (a) horizontal strain $\varepsilon_{\mathrm{x}}$ along upper flange; (b) horizontal strain $\varepsilon_{\mathrm{X}}$ along lower flange; and (c) vertical strain $\varepsilon_{\mathrm{Z}}$ along line at two-thirds of beam's height. (Note: $1 M N=224$ kips.)

(a)

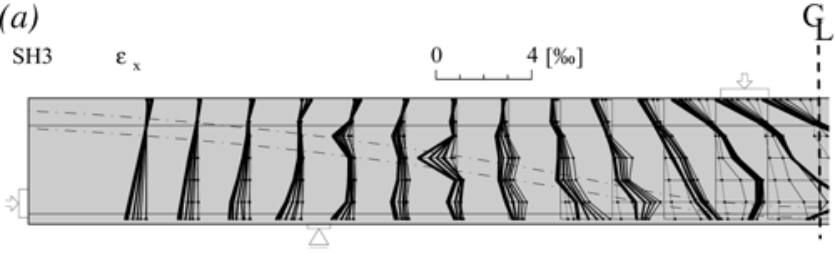

(b)



Fig. 8-Plots of strains measured in Beam SH3 at various load levels: (a) longitudinal strains $\varepsilon_{\mathrm{X}}$; and (b) vertical strain $\varepsilon_{\mathrm{Z}}$ (Note: Dimensions in inches; $1 \mathrm{in} .=25.4 \mathrm{~mm}$.) 
external axial force. A significant change in the strain direction is observed at the level of the tendons. Figure 9(b) plots the same result before failure when a very strong external axial force was applied, reducing the relative deviation at the tendon level. Some inclination of the direction of the compressive strains in the upper flange can also be noted in this Fig. 9(b).

In addition to in-plane strain measurements, measurements of the transverse expansion were performed in the failure zone. Figures 10(a) and (b) show the location where the measurements were taken. The measurements show that the transverse expansion developed at a similar rate than the in-plane strains (Fig. 10(c)). This result in the failure zone is in good agreement with the behavior observed in several tests performed on reinforced panels with post-tensioning tendons. ${ }^{2}$

The strain measurements of the tendons during the tests as well as the strain measurements of the residual strain after testing (obtained by cutting the tendons) allow estimation of the bond stress of the tendons. A reasonable estimate ${ }^{6}$ is obtained assuming a constant bond strength of $\tau_{b p}=0.15 f_{c m}{ }^{2 / 3}$. This strength is rather small compared with usual values in similar cases (for instance, values of $\tau_{b p}=1 / 3 f_{c m}{ }^{2 / 3}$ are proposed in Reference 8). This value can be explained because smooth wires were used (instead of twisted strands).

\section{ANALYSIS OF POST-TENSIONED GIRDERS USING STRESS FIELDS}

The stress field method is an equilibrium solution based on the lower bound theorem of plasticity, which is suitable for the dimensioning of reinforced and prestressed concrete members. ${ }^{9}$ A stress field is developed for a given structural element using smeared struts that allow one to directly obtain the stresses in the concrete.


Fig. 9-Plots of principal compressive strain direction $\varepsilon_{3}$ in Beam SH3 at various load levels: (a) V/V $\mathrm{V}_{\text {test }}=0.54$; and $(b)$ $\mathrm{V} / \mathrm{V}_{\text {test }}=0.98$. (Note: Dimensions in meters; $1 \mathrm{~m}=3.28 \mathrm{ft}$.) (a)

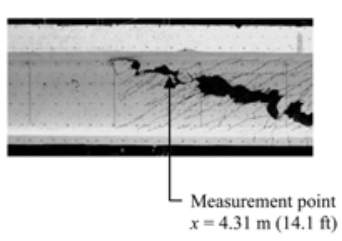

(b)

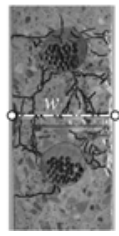

(c)

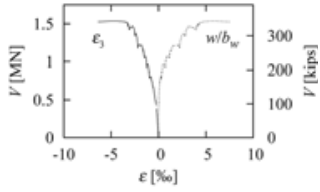

Fig. 10-Transverse expansion of web: (a) location of point of measurement; (b) transverse expansion measurements $\mathrm{w}$; and (c) plot of transverse strain $\mathrm{w} / \mathrm{b}_{\mathrm{w}}$ and in-plane principal compressive strain $\varepsilon_{3}$ in measurement point.
The application of this method to the analysis of posttensioned girders is investigated in the following. Its application in this case is particularly efficient because concrete crushing is investigated and the stresses in the concrete are a direct result from the stress field.

The stress field method can also be applied with the aim of understanding the structural response of post-tensioned girders by increasing the complexity (and accuracy) of the proposed stress fields. First, two discontinuous stress fields are investigated: a straight stress field and a deviated stress field. The discontinuous stress fields are solely based on equilibrium conditions and can be easily developed by hand. Some level of experience is required for their development, however, because no compatibility conditions are explicitly introduced and deviations from the actual behavior may result. ${ }^{9}$ The study is completed by a continuous stress field developed with the help of the finite element method, ${ }^{10}$ where compatibility conditions are respected. The continuous stress field results are also used to investigate the suitability of the discontinuous stress fields.

\section{ANALYSIS OF BEAM SH3 USING STRAIGHT STRESS FIELDS}

The behavior of Beam SH3 is investigated in this section with the help of a straight compression field. This is the typical approach followed by European design codes (for instance, EC- $2^{3}$ and SIA $262^{11}$ ). The force in the tendon is assumed to be equal to the prestressing force after losses (Fig. 11(a)). Using the vertical equilibrium conditions of the free-body diagram shown in Fig. 11(c), the following is obtained

$$
V=V_{s t}+V_{P, \infty}
$$

The value of $\theta$ (the compression field angle) can be calculated for a straight stress field assuming yielding of the stirrups (refer to Fig. 12(a))

$$
\begin{gathered}
V_{s t}=V-V_{P, \infty}=\rho_{w} b_{w} z \cot (\theta) f_{y} \rightarrow \\
\rightarrow \theta=\arctan \left(\frac{\rho_{w} b_{w} z f_{y}}{V-V_{P, \infty}}\right)
\end{gathered}
$$

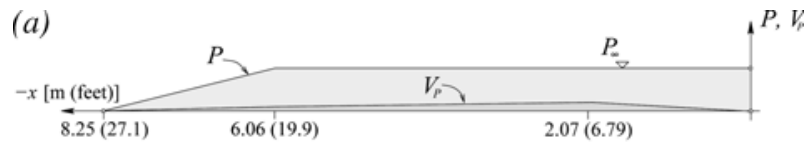

(b)

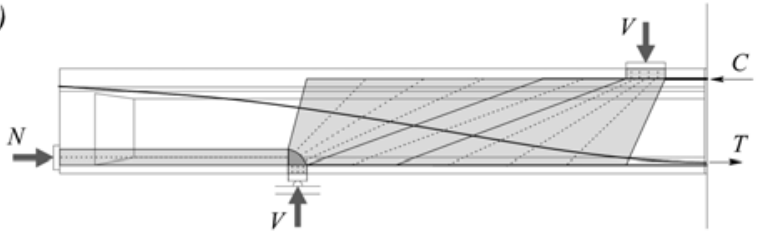

(c)

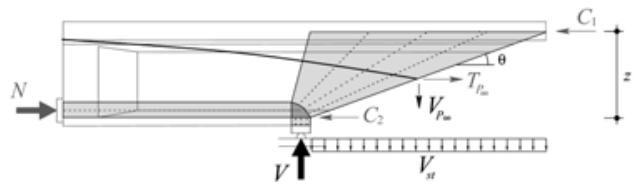

Fig. 11-Analysis of Beam SH3 at failure considering no stress increase in tendons: (a) prestressing force $\mathrm{P}$, prestressing force after losses $\left(\mathrm{P}_{\infty}=1.10 \mathrm{MN}\right.$ [246 kips]) and vertical component of prestressing force $\mathrm{V}_{\mathrm{P}} ;(b)$ resulting stress field; and (c) free body equilibrium. 
With the value of $\theta$, the concrete stresses in the web can be obtained using (Fig. 12(b))

$$
\sigma_{c}=\frac{V-V_{P, \infty}}{b_{w} z \sin (\theta) \cos (\theta)}
$$

Applying the previous expressions to Specimen SH3 ( $V=$ 1.535 MN [343 kips]) and adopting a constant lever arm of $z=1100 \mathrm{~mm}$ (43.3 in.), an angle for the compression field equal to $\theta=20$ degrees is obtained, resulting in a compression stress in the web of $31.2 \mathrm{MPa}$ (4520 psi).

A straight stress field does not allow one to increase the force in the prestressing tendon, which remains $P_{\infty}$. Thus, an inconsistency is found when investigating the flexural strength at midspan, where the sum of the external axial force plus the prestressing force $P_{\infty}$ is not sufficient to satisfy the equilibrium of moments. Furthermore, due to compatibility requirements, the stress in the tendons must increase with the deformation of the beam. A more consistent stress field that satisfies both the equilibrium of forces and moments, and that considers the stress increase in the tendon, can be developed assuming a deviated stress field in the web.

\section{ANALYSIS OF BEAM SH3 USING DEVIATED STRESS FIELDS}

The force in the post-tensioning tendons can be increased with respect to its initial value (force after losses) if other stress fields are considered; some examples are discussed in Muttoni et al. ${ }^{9}$ Figure 13 shows, for instance, a possible stress field of this type for Beam SH3. The force in the tendons (Fig. 13(a)) is calculated using the measured value of the bond strength before yielding of the tendons $\left(\tau_{b p}=0.15 f_{c m}{ }^{2 / 3}\right)$. After yielding, the bond strength is reduced to one-half. ${ }^{12}$

The increase in the tendon force reduces the shear force that is carried by the web, which can be regarded as a positive effect (resulting in less inclined struts and consequently smaller compressive stresses). To increase the force in the tendons, however, the struts have to be deviated. As a consequence, more inclined struts result above the tendon, which is detrimental as the stresses in the compression field increase. Both phenomena tend to compensate, their final effect depending on the geometry and loading pattern of the member.

The complete calculation of the stress field (Fig. 13(b) and (d)) is rather tedious. The critical zone of the stress field (where $\theta$ is minimal), however, can be easily investigated. Figure 13(c) shows the equilibrium of the critical free-body. The forces acting on it are obtained from the equilibrium of the left-hand and right-hand side free-bodies of the system. With the values of the forces, the angle of the struts in the critical region can be determined, resulting in $\theta=19$ degreesslightly smaller than the angle obtained with the straight stress field. Consequently, the compressive stress in the web is $34.4 \mathrm{MPa}$ (4980 psi), larger in this case than the value obtained with the straight stress field.

\section{DISCUSSION ON SUITABILITY OF DISCONTINUOUS STRESS FIELDS \\ Principal compressive strain direction}

The measured angle of the principal compressive strain $\theta$ of Specimen SH3 before failure, measured at two depths of the web, is compared in Fig. 14 to the results of the two stress fields. A satisfactory agreement is obtained in both cases. The development of fans close to the loading plates is confirmed by the measurements as well as the value of $\theta$ in the failure zone.

\section{Shear strength}

The strength of the web, $f_{c e}$, according to the stress field method, can be estimated as

$$
f_{c e}=f_{c} \eta_{f c} \eta_{D} \eta_{\varepsilon}
$$

where $f_{c}$ is the compressive strength of the concrete $(56 \mathrm{MPa}$ [8120 psi] in this case).

The strength reduction factor $\eta_{f c}$ provides an equivalent concrete plastic strength. It can be evaluated as ${ }^{9}$ (a)

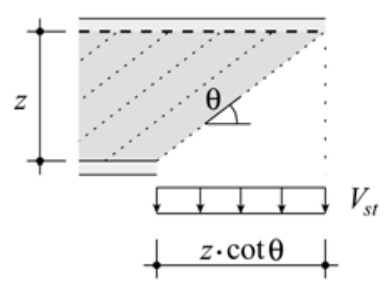

$$
V_{s t}=z \cdot \cot \theta \cdot b_{w} \cdot \rho_{w} \cdot f_{y}
$$

(b)

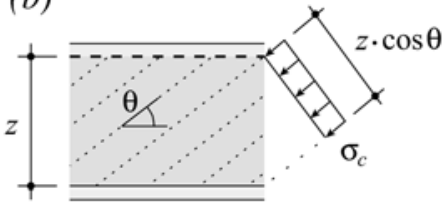

$$
V-V_{p, \infty}=z \cdot \cos \theta \cdot b_{w} \cdot \sigma_{c} \cdot \sin \theta
$$

Fig. 12-Analysis of straight stress field: (a) shear carried by stirrups; and (b) equilibrium of compression field.
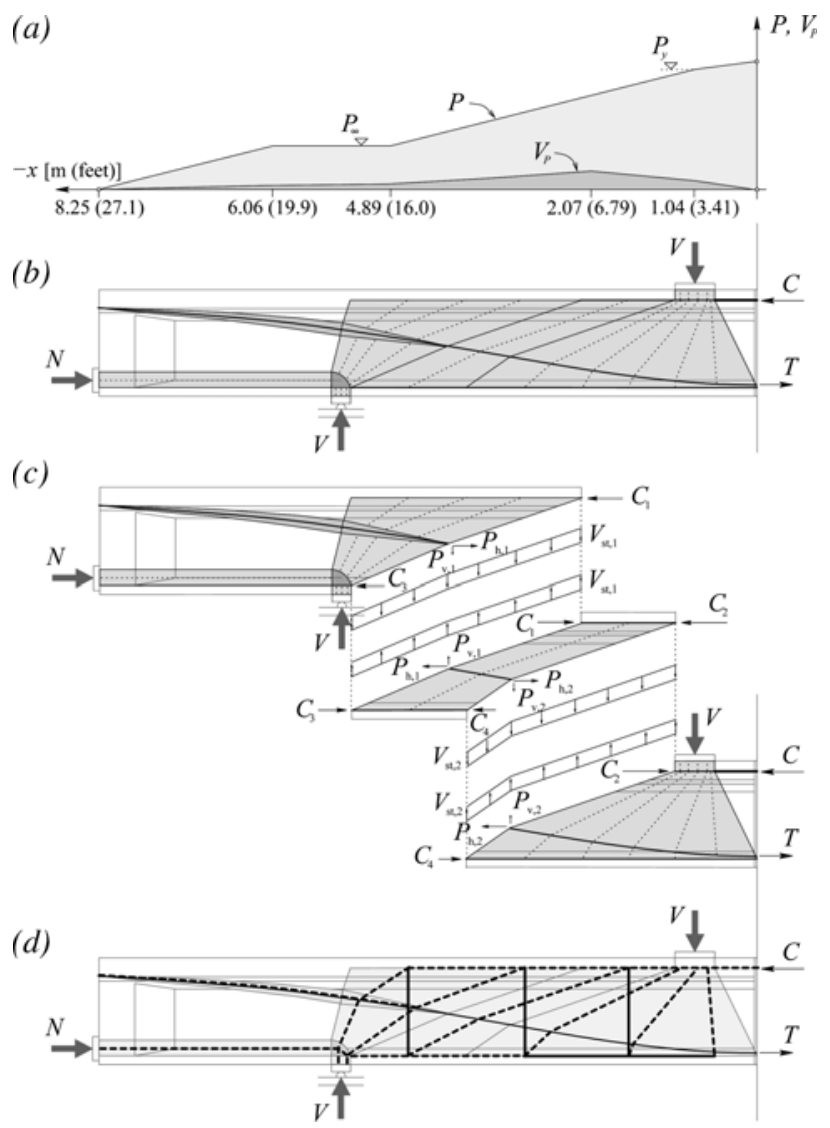

Fig. 13-Stress field analysis of Beam SH3: (a) prestressing force $\mathrm{P}$ and vertical component of prestressing force $\mathrm{V}_{\mathrm{P}} ;(b)$ adopted stress field; (c) analysis of critical deviated stress field; and (d) complete strut-and-tie model. 


$$
\eta_{f c}=\left(\frac{f_{c 0}}{f_{c}}\right)^{1 / 3}
$$

where $f_{c 0}$ is $30 \mathrm{MPa}(4350 \mathrm{psi})$. For Beam SH3, it is $\eta_{f_{c}}=0.81$.

The strength reduction factor $\eta_{\varepsilon}$ accounts for the transverse strain state (its value can be considered 0.60 in the web ${ }^{9}$ ) and the strength reduction factor $\eta_{D}$ accounts for the presence of the duct, its value can be estimated as

$$
\eta_{D}=1-k \sum \frac{d_{D}}{b_{w}}=0.76
$$

where $k$ can be set to 0.50 according to References 3 and 11 (similar values for steel ducts have also been reported in Reference 2) and $\Sigma d_{D}$ is the sum of the diameter of the ducts at a given level in the web.

With these values, the effective strength of the concrete is $f_{c e}=20.7 \mathrm{MPa}$ (3000 psi). This strength is smaller than the stresses obtained with the previous stress fields. This difference is justified by the fact that some load-carrying mechanisms (or physical effects) in the development of the stress fields have been neglected:

Inclination of compression chord-The flanges of the beam (and especially the upper flange in this case) have some capacity to carry shear forces. As shown in the measurements of Fig. 9, the principal compressive strain direction in the upper flange presents an inclination. Taking into account the forces in the compression chord, a fraction of the total shear force can be carried by this effect. The actual contribution of this phenomenon to the shear strength is difficult to estimate when developing discontinuous stress fields. Consequently, it is advised to neglect it.

Contribution of concrete in carrying shear forces across cracks-The stress field method neglects the ability of reinforced cracked concrete to carry tensile forces across cracks. A shear-carrying mechanism of this type, however, is

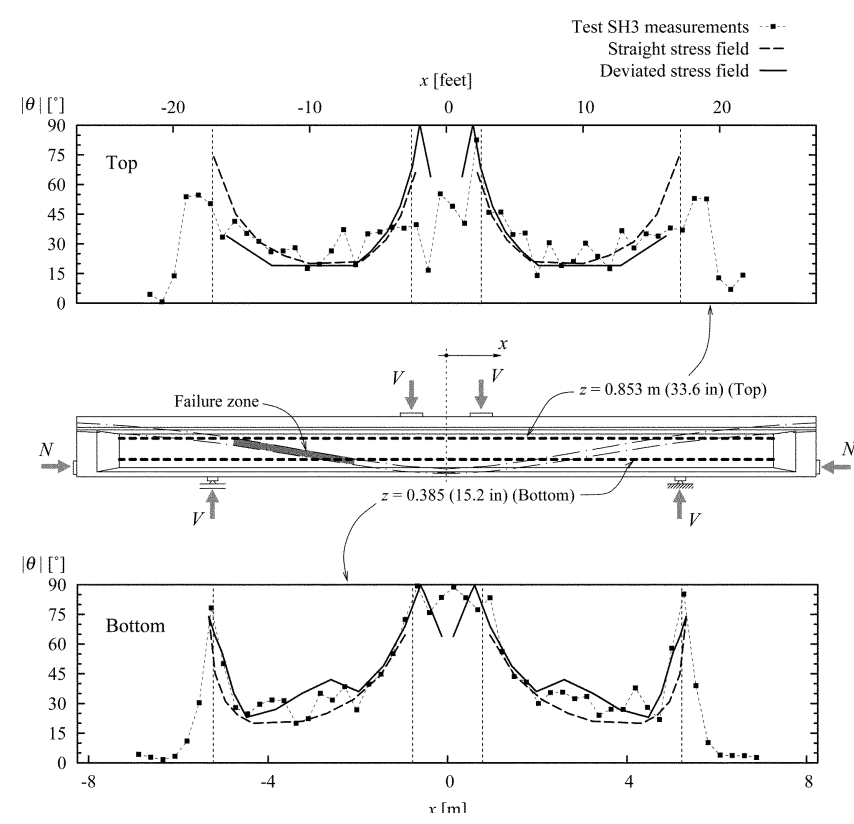

Fig. 14-Plots of principal compressive strain angle along two lines (Test SH3): test measurements and discontinuous stress fields. considered when investigating shear strength according to other approaches. Some design codes ${ }^{13}$ propose combining the shear-carrying capacity of a truss model with a term $V_{c}$ accounting for this effect, resulting in $V=V_{c}+V_{s t}$. The results obtained with this approach will be discussed in the following.

Estimation of $\eta_{\varepsilon}$-The value adopted for the strength reduction factor $\eta_{\varepsilon}$ is 0.60 , corresponding to the value usually accepted in the design of such structures. This value is adopted without deriving it from an equation accounting for the state of cracking in the web and thus it may be conservative for the case studied.

Coupling of strength reduction factors-Another effect that has to be taken into account is whether the multiplicative formulation adopted in Eq. (4) is suitable or not. In all the specimens tested, spalling of the cover along the tendon took place at failure. In an experimental series of 16 panels tested without straining the stirrups, ${ }^{2}$ however, no spalling of the cover was detected. Failure in these panels took place when a crack, in the central part of the panel, developed in the plane of the tendon. These observations indicate that two different failure zones develop. The first (where spalling of the cover develops) is mainly affected by strains in the stirrups, $\eta_{\varepsilon}$, whereas the disturbance caused by the tendon, $\eta_{D}$, is mainly influencing the central part of the web. In this case, the multiplicative formulation adopted $\left(\eta_{\varepsilon} \eta_{D}\right)$ seems conservative because the zones affected by these two effects are different. Both phenomena are not, however, completely uncoupled because the flow of stresses is disturbed by the presence of the tendons and, thus, some effect is induced by the tendon in the plane of the stirrups. This assumption is also confirmed by tests on precracked panels extracted from the girders investigated in this paper. ${ }^{2}$ Other possible crushing modes of the web (where concrete spalling does not develop or only in a limited manner) also lead to adopt a multiplicative formulation.

The previous effects explain some differences between the actual strength and that predicted by the discontinuous stress fields. In any case, neglecting these phenomena when developing discontinuous stress fields seems prudent because their quantification is complex and the actual security margin is adequate.

\section{CONTINUOUS STRESS FIELD ANALYSIS OF BEAM SH3}

The ability of a given stress field to reproduce the actual behavior (and strength) of a member is significantly influenced by its strain compatibility. ${ }^{9}$ The most compatible stress fields are those that present a smooth variation of the stresses between adjacent struts, so-called continuous stress fields. ${ }^{10}$

The hypotheses for the development of continuous stress fields can be implemented in an effective way using the finite element method (FEM) as introduced in Reference 10. The compressive strength of the concrete is introduced as an equivalent plastic strength

$$
f_{c e}=f_{c} \eta_{f c} \eta_{\varepsilon}
$$

where $\eta_{f c}$ is obtained from Eq. (5). The strength reduction factor $\eta_{\varepsilon}$ accounting for the cracking state can be computed and introduced locally for each element on the basis of the laws proposed by various authors. For instance, according to Vecchio and Collins ${ }^{14}$ 


$$
\eta_{\varepsilon}=\frac{1}{0.8+170 \varepsilon_{j}} \leq 1.0
$$

where $\varepsilon_{j}$ is the transverse strain of the concrete.

The application of the continuous stress fields to posttensioned girders, where the duct reduction factor $\eta_{D}$ has to be taken into account, can be performed by reducing the thickness of the web in the zone where the tendons are placed. Figures 15(a) and (b) show the mesh used for modeling Beam SH3, where the thickness of the web in the zone between tendons is reduced to

$$
b_{\text {eff }}=b_{w} \eta_{D}
$$

The actual reinforcement and tendons were introduced throughout the model using link elements ${ }^{10}$ (with an initial strain in the case of the tendons). The layout of the mesh was created to facilitate the placement of the reinforcement and the tendons at its actual location.

The failure load of Beam SH3 obtained with the continuous stress field is rather accurate $(V=1.61 \mathrm{MN}$ [360 kips]), slightly higher than the actual strength $(V=1.535 \mathrm{MN}$ [345 kips]). Some remarks can be derived from the continuous stress field analysis:

1. A minimum angle of 19.6 degrees is found in the critical zone, in good agreement with the discontinuous stress field results;

2. A strain reduction factor $\eta_{\varepsilon}=0.59$ (Fig. 15(c)) is found in the critical zone, confirming the design values usually adopted for this parameter;

3 . The critical shear region is located outside the fans developed by the introduction of the point load. This behavior results from the very different values of $\eta_{\varepsilon}$ inside and outside the fans (refer to Fig. 15(c)) in spite of the fact that stresses are larger in the fan region. Consequently, the validity of the region typically investigated with the discontinuous stress fields is confirmed; and

4. The shear forces carried by the various elements of the girder (the web, the upper and the lower flanges, and the prestressing tendons) can be investigated with the results of the continuous stress fields. Figure 15(d) plots the various contributions where the important role of the upper flange can be noted.

\section{SHEAR STRENGTH BASED ON STRESS FIELDS AND COMPARISON WITH CODES OF PRACTICE}

If a straight stress field (refer to Fig. 11) is developed for Beam SH3 respecting the value of $f_{c e}$ in the web, a value of $\theta=24.8$ degrees is obtained in the critical zone, leading to a failure load of $1.25 \mathrm{MN}$ (279 kips). Thus, the ratio between the measured failure load and the predicted failure load is

$$
\frac{V_{\text {test }}}{V_{S-S F}}=1.23
$$

A better stress field respecting the effective strength of the member is shown in Fig. 16. The compression field angle in the critical region is again 24.8 degrees for both the regions above and below the tendon. The tendon force is thus increased by deviation of the inclined struts outside the critical zone. It leads to a failure load of $1.42 \mathrm{MN}$ (297 kips), and a ratio

$$
\frac{V_{\text {test }}}{V_{D-S F}}=1.08
$$

The difference between the strength of both stress fields is due to the increase in the tendon force in the second case, which increases the part of the shear carried by the posttensioning tendon.

As already mentioned, the continuous stress field provides a failure load of 1.61 MN (360 kips), thus leading to a ratio

$$
\frac{V_{\text {test }}}{V_{C-S F}}=0.96
$$
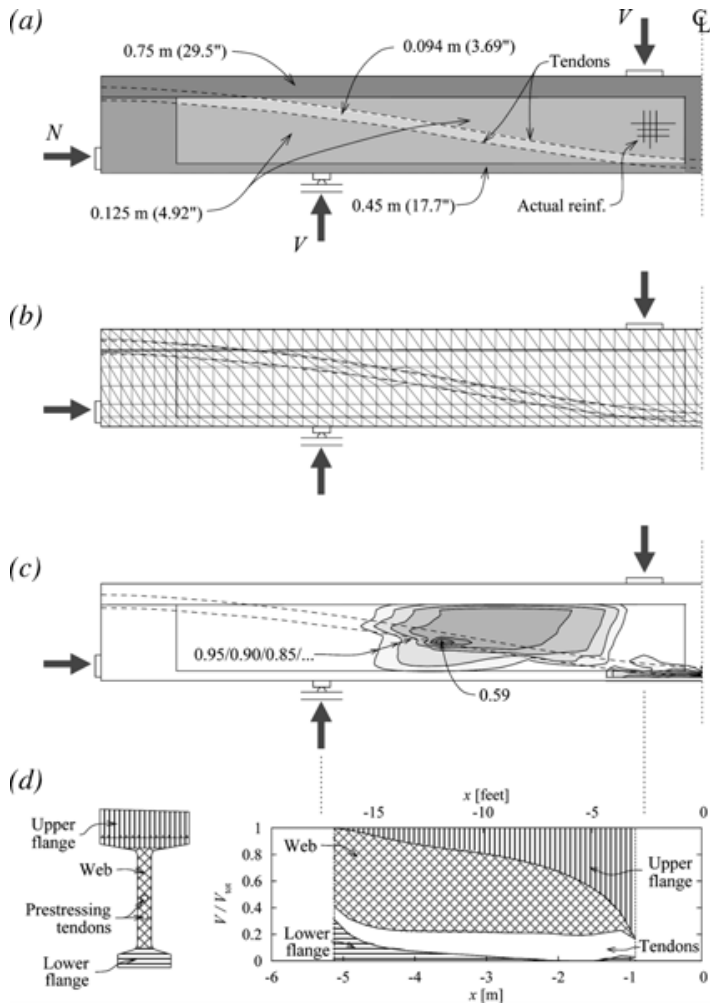

Fig. 15-FEM for continuous stress field analysis: (a) thicknesses and actual reinforcement; (b) FEM mesh; (c) plot of strength reduction factor $\eta_{\mathrm{e}}$ according to Eq. (8); and (d) shear forces carried by various elements of cross section.

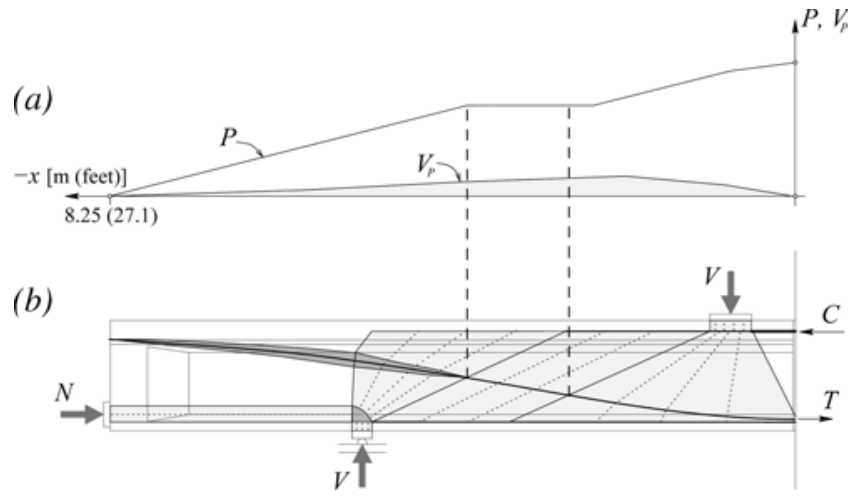

Fig. 16-Deviated stress field analysis with constant angle in failure zone: (a) prestressing force $\mathrm{P}$ and vertical component of prestressing force $\mathrm{V}_{\mathrm{P}}$; and $(b)$ adopted stress field. 
Table 4-Comparison between actual and computed strength

\begin{tabular}{c|c|c|c|c|c|c}
\hline Test & $\frac{V_{\text {test }}}{V_{S-S F}}$ & $\frac{V_{\text {test }}}{V_{D-S F}}$ & $\frac{V_{\text {test }}}{V_{C-S F}}$ & $\frac{V_{\text {test }}}{V_{\text {SIA 262 }}}$ & $\frac{V_{\text {test }}}{V_{\text {ACI } 318-05}}$ & $\frac{V_{\text {test }}}{V_{\text {AASHTO }}}$ \\
\hline SH1 & 1.21 & 1.07 & 0.95 & 1.21 & 1.62 & 1.16 \\
\hline SH2 & 1.06 & 1.00 & 1.05 & 1.06 & 1.37 & 1.06 \\
\hline SH3 & 1.23 & 1.08 & 0.96 & 1.23 & 1.65 & 1.18 \\
\hline SH4a & 0.92 & 0.91 & 0.92 & 0.92 & 1.16 & 1.02 \\
\hline SH4b & 1.29 & 1.28 & 0.96 & 1.32 & 1.65 & 1.29 \\
\hline SH5 & 1.40 & 1.22 & 1.02 & 1.40 & 1.85 & 1.33 \\
\hline MEAN & 1.19 & 1.09 & 0.98 & 1.19 & 1.55 & 1.17 \\
\hline COV & 0.14 & 0.13 & 0.05 & 0.15 & 0.16 & 0.10 \\
\hline
\end{tabular}

Note: $S$-SF: straight stress field (Fig. 11); D-SF: deviated stress field (Fig. 17); $C$-SF continuous stress field; COV: coefficient of variation.

Table 5-Comparison of hypotheses adopted in various analyses

\begin{tabular}{|c|c|c|c|c|c|c|}
\hline Parameter & $S-S F$ & $D-S F$ & $C-S F$ & SIA262 $2^{11}$ & $\begin{array}{c}\text { ACI } \\
318-05^{13}\end{array}$ & $\begin{array}{c}\text { AASHTO } \\
(04)^{4}\end{array}$ \\
\hline Theory & DSF & DSF & $\mathrm{CSF}$ & DSF & MTA & MCFT \\
\hline$\theta$ & Variable & Variable & Variable & Variable & 45 degrees & Variable \\
\hline$\theta_{\lim }$ & - & - & - & $\begin{array}{c}25 \\
\text { degrees }\end{array}$ & 45 degrees & $\begin{array}{c}21.8 \\
\text { degrees }\end{array}$ \\
\hline$\eta_{\varepsilon}$ & 0.6 & 0.6 & Eq. (8) & 0.6 & - & Eq. (8) \\
\hline $\begin{array}{c}k= \\
\left(1-\eta_{D}\right) / \Sigma d_{D}\end{array}$ & 0.5 & 0.5 & 0.5 & 0.5 & 0.0 & 0.25 \\
\hline$\eta_{f c}$ & Eq. (5) & Eq. (5) & Eq. (5) & Eq. (5) & 1.0 & 1.0 \\
\hline
\end{tabular}

Note: Refer to Table 4; DSF: discontinuous stress field; CSF: continuous stress field; MTA: modified truss analogy; MCFT: modified compression field theory.

The failure loads obtained with the stress fields for all the specimens tested, as well as a comparison with the results provided by various codes of practice $4,11,13$ are detailed in Table 4. A summary of the main hypotheses adopted is presented in Table 5.

From this comparison, the following conclusions can be drawn:

1. ACI $318-05^{13}$ provides very conservative results mainly due to the choice of a 45-degree truss (it should be noted that ACI $318-05^{13}$ is not a bridge design code);

2. SIA $262^{11}$ and AASHTO LRFD ${ }^{4}$ are both based on mechanical models (the stress field method and the modified compression field theory, respectively) and provide a good estimate of the shear strength of these members; and

3. Continuous stress fields provide the best agreement with test results. More effort, however, has to be devoted to the preparation of the data.

\section{CONCLUSIONS}

This paper presents the results of an experimental and theoretical research on the behavior of post-tensioned beams with thin webs. Six full-scale tests performed on actual bridge girders failing in shear by web crushing are presented. Their experimental results are analyzed and various approaches for their modeling are discussed.

The main findings of the experimental campaign are:

1. The tendon increases its strain during the loading of a beam, resulting in a deviation of the compression field in the web;

2. Angles of the compression field in the web close to 20 degrees have consistently been measured in the zone of the web over the tendon. The presence of fan-shaped stress fields where a point load is introduced is also confirmed;

3. An inclination of the force in the compression chord was observed in the specimens, which had a non-negligible influence in carrying shear forces; and

4. Failure by concrete crushing in the post-tensioned girders was accompanied of spalling of the concrete cover along the tendon. The spalling of the cover was related to the straining of the stirrups, which led to significant tensile stresses in the concrete cover induced by bond. Conversely, no spalling was observed on a series of panels tested without applying strains in the reinforcement.

The test results have been analyzed using the stress field method and the formulae provided by some design codes. Several conclusions are drawn from the theoretical study:

1. The suitability of a multiplicative approach to consider the interaction between the strength reductions accounting for the cracking state of the concrete and the presence of ducts is confirmed. Although certain inconsistencies are present, in general, a reasonable estimate is provided by this hypothesis;

2. The deviation of the stress field in the web due to the tendon has a positive effect in the shear strength of the member because the stresses in the tendon are increased and, thus, the shear carried by this element. There is also a negative effect in the case of failure by web crushing, however, because more inclined and more stressed struts result. Both phenomena tend to compensate, the final effect depending on the geometry and loading pattern of the member;

3. Reasonably accurate and conservative results are obtained by developing discontinuous stress fields. The difference between the actual strength and the values predicted by the discontinuous stress fields is mainly explained by the portion of shear carried by the inclination of the compression chord. This contribution should be neglected when developing discontinuous stress fields by hand, leading to conservative solutions;

4. The development of a continuous stress field constitutes a consistent and rational step forward when investigating the shear contribution of the compression chord. More accurate results are obtained and the role of the various elements of the structure can be investigated. The development of continuous stress fields in this paper confirms that angles close to 20 degrees for the compression field in the web can be developed. The validity of the strength reduction factor accounting for the cracking state, and usually adopted as 0.60 , is confirmed by these analyses. Furthermore, the results of the continuous stress fields indicate that the critical shear region is located outside the fans developed by the load introduction, confirming the validity of the region typically investigated with discontinuous stress fields;

5. The dimensioning of thin-webbed members can be performed using straight stress fields or the formulas proposed in Eurocode 2, ${ }^{3}$ SIA 262, ${ }^{11}$ or AASHTO LRFD. ${ }^{4}$ Reasonable and conservative designs result with a limited amount of effort; and

6. The checking of existing members may follow an incremental approach. First, a straight stress field (or the formulas provided by codes of practice Eurocode $2,{ }^{3}$ SIA $262,{ }^{11}$ or AASHTO LRFD ${ }^{4}$ ) can be used. If an insufficient strength results, then a deviated stress field can be developed to improve the accuracy in the shear-carrying mechanisms. Finally, if the strength remains insufficient (but close to the required value), a continuous stress field may be developed 
to estimate the contribution of some neglected shear-carrying mechanisms (as the inclination of the compression chord).

\section{ACKNOWLEDGMENTS}

The work presented in this paper was funded by the Swiss Federal Roads Authority and the Canton Tessin (Switzerland). The authors are appreciative of the support received. The authors would also like to express their gratitude to E. Hars for the dedicated experimental work he performed.

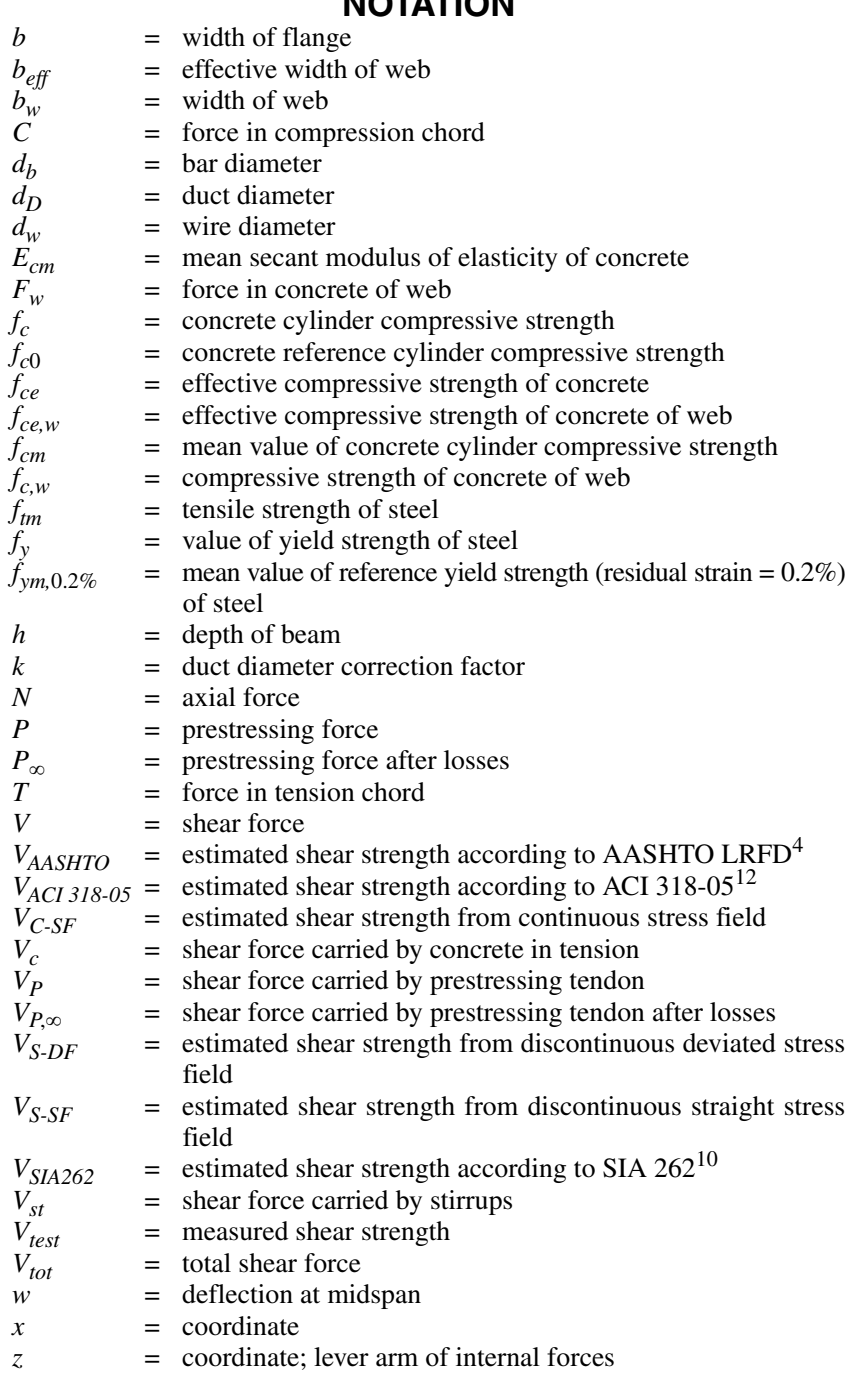

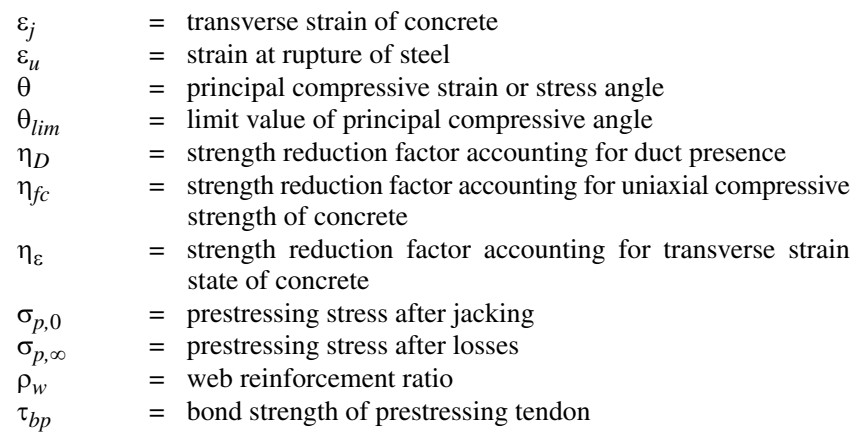

\section{REFERENCES}

1. Komendant, A. E., Prestressed Concrete Structures, McGraw-Hill, New York, 1952, $261 \mathrm{pp}$.

2. Muttoni, A.; Burdet, O. L.; and Hars, E., "Effect of Duct Type on Shear Strength of Thin Webs," ACI Structural Journal, V. 103, No. 5, Sept.-Oct. 2006, pp.729-735.

3. Eurocode 2, "Design of Concrete Structures," Part 1-1, General Rules and Rules for Buildings, prEN1992-1-1, 2004, $222 \mathrm{pp}$.

4. AASHTO LRFD, "Bridge Design Specifications and Commentary," 3rd Edition, American Association of State Highway Transportation Officials, Washington, DC, 2004, 1264 pp.

5. Sigrist, V.; Marti, P.; and Bättig, A., "Strengthening of the Highway Bridge Brunau South," Beton-und Stahlbetonbau, V. 101, No. 5, 2006, pp. 360-638. (in German)

6. Hars, E., and Muttoni, A., "Shear Tests on Thin-Webbed PostTensioned Girders," Test Report, Ecole Polytechnique Fédérale de Lausanne, Lausanne, Switzerland, 2006, 108 pp. (in French)

7. Czaderski, C., and Motavalli, M., "Determining the Remaining Tendon Force of a Large-Scale, 38-Year-Old Prestressed Concrete Bridge Girder," PCI Journal, V. 51, No. 4, 2006, pp. 56-68.

8. Zwicky, D., "Load-Carrying Capacity of Heavily Post-Tensioned Concrete Beams," Institut für Baustatik and Konstruktion, ETH Zürich, 2002, 228 pp.

9. Muttoni, A.; Schwartz, J.; and Thürlimann, B., Design of Concrete Structures with Stress Fields, Birkhaüser, Boston, MA, 1997, 145 pp.

10. Fernández Ruiz, M., and Muttoni, A., "On Development of Suitable Stress Fields," ACI Structural Journal, V. 104, No. 4, July-Aug. 2007, pp. 495-502.

11. Swiss Society of Engineers and Architects (SIA), "Code 262 for Concrete Structures," Zürich, Switzerland, 2003, 94 pp.

12. Marti, P.; Alvarez, M.; Kaufmann, W.; and Sigrist, V., "Tension Chord Model for Structural Concrete," Structural Engineering International, IABSE, V. 8, No. 4, 1998, pp. 287-298.

13. ACI Committee 318, "Building Code Requirements for Structural Concrete (ACI 318-05) and Commentary (318R-05)," American Concrete Institute, Farmington Hills, MI, 2005, $430 \mathrm{pp}$.

14. Vecchio, F. J., and Collins, M. P., "The Modified Compression Field Theory for Reinforced Concrete Elements Subjected to Shear," ACI JournaL, Proceedings V. 83, No. 2, Mar.-Apr. 1986, pp. 219-231. 